\title{
ComDev in the Mediatized World
}

\author{
Oscar Hemer \& Thomas Tufte ${ }^{1}$
}

\begin{abstract}
In late 2011 we are in the beginning of a revolution that may or may not turn out to be more far-reaching than the one unleashed in 1989. A common denominator in this resurging revolution is the mobilizing power of the so-called social media. Even if labels such as the Twitter or Facebook revolution are rightfully refuted, the on-going Arab Spring is a clear-cut example of an unprecedented communication power, largely out of the authorities' control.

While the crucial role of media and communication in processes of social change at last becomes evident, it is however not associated with the field of communication for development and social change. While that field historically has been about developing prescriptive recipes of communication for some development, it is time attention is refocused to the deliberative, non-institutional change processes that are emerging from a citizens' profound and often desperate reaction to the global now.
\end{abstract}

Keywords: globalization, mediatization, development

\section{Introduction}

When the Berlin wall fell, in 1989, we all knew that we were witnessing History in the making. But we did not know that the global transformational processes that were both cause and effect of the end of the Cold War would in the coming decades be referred to as Globalization. The concept had been coined, that same year, by cultural sociologist Roland Robertson (Robertson 1992). But it was only in the mid '90s that it really caught on (Castells 1996, 1997, 1998; Held et al. 1999). And it remained controversial for many years, with sharp positioning pro and con. The skeptics stated that it was just another euphemism for neo-liberal global capitalism - that there was nothing new under the sun. (Paradoxically, the anti-globalization movement appears in retrospect as perhaps the most striking evidence of globalization.) Now, the word has lost its once inciting edge. Even its former fervent opponents talk quite matter-of-factly about globalization as one of the conditions for world development.

As we are writing, in late 2011, we are in the beginning of another historical revolution - that may or may not turn out to be even more far-reaching than the one unleashed in 1989. Starting in Tunisia, it was wittily called the tunisami as it spread to Egypt and the rest of the Arab world. Western governments - and Western media - were taken completely by surprise. The social mobilization in the Middle East concurred with a renewed financial crisis in Europe and the US, and popular protests spread to Greece (Aganaktismenoi), Spain (Indignados) and across the Atlantic to Chile (Invierno chileno) 
and the US (Occupy Wall Street), but also in more inarticulate and destructive form, to the UK (England riots).

A common denominator in this resurging revolution, that has proved itself capable of toppling three authoritarian governments (in Libya with the kind assistance of late general Gadaffi's former Western allies), is the mobilizing power of the "new" so-called social media. Even if labels such as the Twitter or Facebook revolution are rightfully refuted, the on-going Arab Spring, which in some places may have turned to summer, and in others to autumn, is a clear-cut example of a new and unprecedented communication power, which is largely out of the authorities' control. (And so were the recent England riots, seemingly without other purpose than the hell of it, and in any case spurring diametrically different reactions in the Western media.) ${ }^{2}$ What we are now witnessing are largely the consequences of globalization, but equally, they are associated with another, as elusive and all-encompassing concept: Mediatization.

It is in this context, of a global now, where social mobilizations are overthrowing governments and changing political dynamics (even when governments stay in power), where the role of social media is being celebrated as well as contested, and where the fundamental dynamics between media and communication, citizenship and social change are up for re-examination, that this special issue of Glocal Times and Nordicom Review very timely emerges with its reflections on communication for development.

\section{ComDev Emerging in the Øresund Region}

When we started our collaboration, in 2000, on what was to become the web-based international Master programme in Communication for Development at Malmö University, we made globalization and the emerging network society the framework for a renewed analysis of both communication and development. At the time, everything associated with "development" and "the third world" was widely regarded as obsolete, and the field of development communication, with its post-World War II heyday and second momentum in the 1970s, was in a state of crisis and decline. (A colleague of ours, who is now a prominent researcher in the field, was kindly advised to choose another area for his $\mathrm{PhD}$, as development communication was allegedly a dead-end street.)

ComDev as it was outlined and developed at Malmö University's School of Arts and Communication (K3), did not emerge from within the existing field. It was rather a result of the conflation of a global cultural studies viewpoint on the one hand and a media practitioner's perspective on the other. One of us had a background as a literary writer and journalist, with an orientation towards Africa and Latin America and a special interest in issues concerning cultural globalization; the other had recently finished his $\mathrm{PhD}$ in Cultural Sociology, on how women in Brazil make sense of telenovelas, and was engaged in a large research project on Globalization at Copenhagen University. ${ }^{3}$ We both had long-time experience from living in so-called developing countries, and practical knowledge of international development cooperation.

The planning of the first ComDev course at Malmö University was supported by the Swedish International Development Agency (Sida). The pilot course was given in Swedish and primarily addressing Swedish (and Danish) journalists and information officers. From 2002 it has however been an international programme, entirely taught in English, and recruiting students from literally all over the world. The ComDev master 
is by now a well-established part of Malmö University, with to date close to 150 graduates, a huge body of accumulated knowledge and experience, and a record number of newly enrolled and applying students.

In Roskilde, research in communication for development had evolved sporadically since the 1980s. The fact that RUC was hosting the largest study programme in development studies in the Nordic region, and the largest communication study programme in Denmark, made for a prospective future. From the early 2000s more explicit ComDev courses were offered and a growing number of students linked communication and development studies in their thesis work. Some 40-50 theses have over the past decade been oriented towards communication for development and social change.

In 2005, we co-edited the anthology Media and Glocal Change, which has since served as a fundamental reader for the master students, not only in Malmö and Roskilde, but at many of the still relatively few universities around the world that offer courses in communication for development and social change. The book was launched simultaneously with the establishment, in Los Baños, The Philippines, of the first international University Network in the field, with Malmö and Roskilde as two of the twelve founding members. ${ }^{4}$ The ComDev master's webmag, Glocal Times, was launched in conjunction with the Media and Glocal Change anthology in 2005, with the intent to become "an indispensable digital reference and a vivid forum for the discussion and dissemination of issues concerning communication for development and social change". With its to date 16 issues (this double issue, in collaboration with Nordicom Review, being \# 17/18), Glocal Times, has indeed established itself as an indispensable pillar of the ComDev venture. Many of the field's foremost scholars and practitioners count among the contributors, and the online webmag, which is hereby taking the important step of becoming an open journal, has served as a forum for graduates from Malmö's Master programme and Roskilde students with a ComDev orientation to present their theses to a global audience.,

Equally important was the emerging research in the region in the wider field of communication, culture and social change. From 2000 and onwards, both small and large research projects have been carried out in areas such as health communication (Tufte 2006 \& In Press/2012), culture; memory and social change (Hemer 2008 \& 2011; Høg Hansen 2006 \& 2008); participatory communication (Tufte \& Mefalopulos 2009) ; social media (Gansing 2007; Wildermuth 2010a; Ekström, Høg Hansen \& Boothby 2011); communication, citizenship and empowerment (Navarro 2009 \& 2011; Tufte \& Enghel 2009; Wildermuth 2010b), gender, communication and popular culture (Andreassen 2005; Ekström 2010), celebrities and development aid (Richey \& Ponte 2011).

What started as interpersonal collaboration across the Öresund strait that separates Sweden from Denmark has come together as a research environment and since 2008 been institutionalized in Ørecomm, a transnational research platform established by the universities of Malmö and Roskilde, but serving as a transnational research community reaching out and wanting to collaborate in research projects, conferences and seminars, as well as in teaching and partnerships with practitioners. Today our community comprises of some twentyfive members, whereof ten are PhD students. So we also begin to see the contours of what hopefully can develop into a transnational $\mathrm{PhD}$ program in the field. ${ }^{5}$ 


\section{ComDev between Mediatization and Globalization}

In retrospect, our twelve years of collaboration appear as a success story. But both the ComDev Master in Malmö and the emerging inter-regional research collaboration were, in fact, the result of a series of happily coinciding circumstances. Quite in the same way that Globalization occurred, according to Castells; not by historical determinism - as Marxists or victorious Liberals would have it - but actually largely by chance.

It is an intriguing and important point, that the world might have looked quite different. And, consequently, that it may - and most probably will - look very different twelve years from now. The 1990s were framed by two landmark events in Europe and the US: The fall of the Berlin Wall in ' 89 and 9/11 of 2001. The first decade of the new millennium was marked by the War on Terrorism, but also and more importantly by the rise of the new economic powers (Brazil, Russia, India and China). In terms of communication, the transformation of the ' 90 s has continued at an even accelerating pace. The digital revolution is perhaps the closest we can come to a permanent revolution. All sectors of culture and society are saturated with, and increasingly influenced by, mediated communication. For ComDev, mediatization, like globalization, is increasingly challenging our research and study agenda. What are the causal relations between media development, agency and social change? And how do we study these dynamics? These are core questions for Ørecomm. Media influencing society is, in itself, not a new phenomenon - nor a new idea. Depending on how we define "the media", it can be traced back all the way to Aristotle's Poetics, or at least to Marshall McLuhan's media theory of the 1960s, with catchy one-liners such as the medium is the message. Among ComDev scholars, Jesús Martín-Barbero was the first to make systematic use of the concept mediation (1993), developing a profound analytical framework - a nocturnal map he calls it - to study the relations between subjectivities, cultural trajectories and popular culture, and media use in that context, thus moving the focus from media-centric analyses of media and society, to a focus on media and everyday life. Martín-Barbero was a leading exponent of the rich Latin American cultural studies research emerging from the 1980s and onwards. It had many similarities with the cultural studies emerging out of the UK at the same time, both traditions preceding the current proliferation of studies in mediatization that have been sparked by the increasing pervasiveness of the media not only in cultural practices of ordinary people, but also on the logics and practices of organisations and institutions in society. In the description of the current research project Mediatized Worlds, German media researchers Friedrich Krotz and Andreas Hepp thus describe mediatization as "a comprehensive development process similar to globalization and individualization" (www.mediatizedworlds.net). ${ }^{6}$ In fact, globalization and mediatization are of course inseparably entangled. What we see now is, if you will, the synergy effects of these two intertwined development processes. In his trilogy on the Network Society, Castells did curiously enough not have much to say about media and communication in particular. In Communication Power (2009), his sequel to the trilogy, however, he really puts communication in focus as the key to politics, economy and all fields of human interaction in the network society, stating that "power in the network society is communication power." Consequently, for ComDev it remains a challenge to understand the role of media and communication power at meta-, meso and micro-level in society. It speaks to classical concerns of the causal relations between media and communication on the 
one hand and social and cultural change on the other. The processes of globalization and mediatization are at the heart of such analyses.

Development is also making a grand comeback, lately, after having been questioned and dismissed by neo-liberals and anti-liberals alike. In the current global financial crisis - which largely is a North American and Western European crisis - we are witnessing what sociologist Jan Nederveen Pieterse (2008) has described as the implosion of the neoliberal Anglo-American model and the return of the development state (the latter, not necessarily a democratic one). This will no doubt have enormous implications for international development cooperation. The bilateral and multilateral development industry, until recently dominated by the Western powers and Japan, is now entangled with and challenged by the new models for social and economic development that poor countries aspire to. China, India, and to a lesser but possibly increasing degree, Brazil are the all-encompassing role models. With China's recent entry as a powerful actor on the African development scene, offering enormous grants and investments, and posing no unpleasant conditionality except access to extraction of natural ressources, the political economy, logics and dynamics of the development industry is fundamentally changing. Thus, development has re-entered the scene, but in new and altered forms.

\section{Emerging Agendas for ComDev Scholarship}

The renewed prominence of both communication and development, due to globalization and mediatization combined, ought to imply a new momentum for communication for development. Intense media developments, widespread political activism, thriving transnational advocacy networks and massive bottom up 'agency' is posing new challenges to our conceptualization of ComDev. The changing landscape of the development industry as described above is likewise contributing to the new challenges for both researchers and practitioners.

It is easy to foresee that the world in the coming years will be faced with ever more severe and complex communication challenges, which today's development agents are poorly prepared to meet. A main challenge to this field may in fact be to overcome the obstacle of the development industry itself. The traditional western development agents are grappling with the new impetus of development and social change - that which is driven by social movements of all kinds, bottom up and grassroots' initiatives, which in most aspects operate so very differently than traditional development organizations do, be they governmental or non-governmental.

Paradoxically, the role of media and communication in development cooperation has seen a strange turn after the first World Congress on Communication for Development, held in Rome in 2006 and organized by FAO, the World Bank and the Communication Initiative, in partnership with a broad strand of important organisations in the field. The summit in Rome managed to mobilize almost a thousand participants from research and practice, government and non-government. It was supposed to mark the definite break-through of the science and practice of ComDev. Instead, what happened had more character of an implosion of the ComDev field, which only recently is gaining a new momentum.

Today, we are actually seeing a long series of new institutional initiatives, in the world of ComDev, both in practice and university curricular development. For exam- 
ple, UNICEF has recently revisited their C4D strategy and work, calling for a stronger linkage with the universities and building widespread capacity within their own global organization. At university level, new MAs in ComDev have developed in places like Albania, South Africa, Kenya, Spain, Paraguay, the UK and Colombia - all within the last three years. The field is finally becoming more significantly institutionalized in the world of academia, although it is still grappling with finding its identity between media and communication studies on one side, and cultural studies, political science and not least development studies on some of the other sides. The interdisciplinarity embedded in ComDev, combined with the outlined processes of globalization, mediatization and the proliferation of bottom-up agency are all contributing to put ComDev at a cross-roads.

Mediatization and the recurring social mobilization by means of new media are at the core of issues challenging the field of ComDev. ${ }^{7}$ Traditionally, development communication has been associated with large institutions, bilateral or multilateral, and/or smaller NGOs that have worked closely with or been completely dependent on these larger institutions. Now, this 'invited space for participation,' which the institutionalized ComDev practices have offered citizens is being serverly challenged by the citizendriven spaces, or the social movement media as scholar John Downing describes them (Downing 2010)

Even when participation has been the leading buzz-word - participatory communication - the agency has largely remained in the institutions and organizations that have 'invited' citizens to participate, mobilize and act. The purpose of the strategic communication initiatives may ultimately be to stimulate grassroots' activity - but when the initiative is really coming from the grassroots themselves, the development agents have often been taken by surprise. 2011 has been a paradigmatic year in that sense. The still common understanding of ComDev, as strategic communication interventions by development agents from the developed world - i.e. the West + Japan - in developing countries, still referred to as the third world ${ }^{8},-$ is obviously obsolete. That conception was rendered obsolete already by 1989, with the closure of the Cold War. But the old conception of Development communication - as the means to achieve development, i.e. modernization, through communication, i.e. information campaigns for the diffusion of better practices in agriculture, health care, sanitation etc. in the developing countries - largely prevails. At the major international conference venues for media and communication scholarship, IAMCR, ICA, ECREA, ALAIC, etc., the relation between social media, citizens/citizenship and social change has been very much in focus in the most recent conferences. But most of these discussions, which are at the core of what we have been doing in Malmö and Roskilde the last twelve years, are not associated with ComDev. That was for example very clear at the IAMCR conference Cities, Creativity, Connectivity in Istanbul in July 2011. While the crucial role of media and communication in processes of social change and development at last becomes evident, it is paradoxically not associated with the field of communication for development and social change - with a few exceptions, not even by the development agencies themselves.

As ComDev scholars, and practitioners, we do have a communication problem here. But it is not only a matter of communication. This field is in a state of crisis. And it should be. Because what we are coping with is precisely the transitional processes of the global present, in all sectors of society and at all levels. And maybe the challenge for us, at this moment, is to take a step back and reflect, to analyze and understand, 
rather than to impose development strategies. While ComDev historically has been about developing prescriptive recipes of communication for some development, it is high time we refocus our attention to the deliberative, non-institutional citizen-driven change processes, full of media uses and communicative practices, but emerging from a citizens' profound and often desperate reaction to this global Now. And we must become better at defining our field and carving out our space within culture, media and communication research at large.

\section{Conclusion}

Communication for Development is not exclusively an academic discipline in the traditional sense, although it is also in the process of being established as such. We rather describe it is a multidisciplinary field of theory and practice. And there is more than ever a need for cross- or inter-disciplinarity, something which has slowed down the institutionalization of the field in universities worldwide.

We should keep in mind that the motivating force behind the upheavals, in the Middle East and elsewhere, is dissatisfaction and frustration over the underlying realities of poverty, unemployment, and subdued human rights. The development challenges, the exclusion of many people from development processes, lie at the heart of what is happening globally right now.

We are seeing a reshaping of the media environments - mediascapes, to use Indian American anthropologist Arjun Appadurai's (1996) term - in which "old" and "new" media converge in ever changing forms, radically transforming the arenas of public opinion and agency - redefining the very concept of a public sphere - and yielding new forms of expression that transgress former genre and media boundaries.

We should also be aware that the new communication power can be used for destructive purposes as well. Lately, since 22 July 2011, the focus - at least in Scandinavia - has largely been on what might be called the dark side of mediatization: The concoction of anonymous hate-speech, racism and xenophobia on certain websites that fuels aggressive right-wing fundamentalism all over Europe. Whereas the proliferation of new media enhances openness and widened views for those who are open-minded on the outset, it may just as well serve to further narrow the perspective of the narrow-minded. The massacre on politically active teenagers at Norwegian Utøya demonstrated the fine line between the completely distorted world-view of these online communities, and murderous action, as committed by a self-appointed Crusader. ${ }^{9}$

At the concluding panel on "New Media in the Middle East" at IAMCR's conference in Istanbul in 2011, Marwan Kraidy from Lebanon, who is both media researcher and Middle East expert, associated the current hype on social media with Plato's analogy of the cave - i.e. the notion that we are caught in a cave and seeing the real world, or the world of ideas, merely as shadows projected on the cave wall.

We find the digital cave to be a useful metaphor for the paradox of this historical moment that none of us can grasp. Whereas it is important for us as ComDev researchers to get out of that cave - it is also important to examine and understand the mechanisms that shape and maintain this virtual cave. 


\section{Notes}

1. Oscar Hemer, Ph.D., is Assistant Professor and Coordinator of Malmö University's Master in Communication for Development, Sweden. E-mail: Oscar.Hemer@mah.se. Thomas Tufte is Professor of Communication Studies at the Dept. of Communication, Business and Information Technologies of Roskilde University, Denmark.

2. For an in-depth analysis of the dual power of the social media, both to mobilize towards democracy and to oppress, see the work of Palestinian American media scholar and documentary film-maker Helga Tawil-Souri.

3. The project, headed by Stig Hjarvard, ran from 1999 to 2001 and resulted in several publications.

4. The network as such is no longer operative, but the Los Baños meeting served to initiate informal but sustained collaboration among many attendants, for example staff exchange and course development with Guelph University in Canada.

5. As can be seen from the examples above and the discussion below, our (re-)definition of this field is much wider than the traditional understanding of development communication. This reorientation is, we believe, an important explanation of ComDev's success.

6. For a comprehensive overview of the emerging area of study, see Couldry, Hepp \& Krotz 2010.

7. They are also a challenge to for Culture and Media studies, which in the last decades has tended to focus on audiences and reception - how people make sense of the media, but not so much how they make use of them for political or social action.

8. The term stems from the times of the Cold War, post-colonial liberation and the formation of the nonaligned movement. The first world was Western Europe. North America, Australia and Japan, that is, the more or less liberal capitalist world. The second world was the socialist world of the Soviet Union and its Eastern European satellites. The third world comprised the rest, encompassing completely diverse countries such as Mexico, Saudi Arabia and Papua New Guinea - and the two Koreas! (South Korea was still in the '70s regarded as part of the third world). And both China and India, of course.

9. See for example Thomas Hylland Eriksen's comment on the event, ”Anders Behring Breivik: Tunnel vision in an online world", The Guardian, 25 July 2011.

\section{References}

Andreassen, Rikke (2005) The mass media's construction of gender, race, sexuality and nationality: An analysis of the Danish news media's communication about visible minorities from 1971-2004. Diss. Toronto: University of Toronto.

Appadurai, Arjun (1996) Modernity at large: cultural dimensions of globalization. Minneapolis: University of Minnesota Press.

Castells, Manuel (1996, 1997, 1998) The information age: economy, society and culture. Vol. 1-3. Malden, Mass.: Blackwell.

Castells, Manuel (2009) Communication power. Oxford: Oxford University Press

Couldry, Nick, Hepp, Andreas \& Krotz, Friedrich (ed.) (2010) Media events in a global age. London: Routledge.

Ekström, Ylva (2010) “We are like chameleons!”: changing mediascapes, cultural identities and city sisters in Dar es Salaam. Diss. Uppsala : Uppsala universitet.

Ekström, Ylva, Høg Hansen, Anders \& Boothby, Hugo (2011) "The Globalization of the Pavement - a Tanzanian case study". Communication for Development Portal, 1 March 2011.

Gansing, Kristoffer (2007) "Community New Media - Beyond 'Dissolutionized' Dissent”. University of Amsterdam, Institute of Network Cultures.

Held, David, Goldblatt, David, McGrew, Anthony \& Perraton, Jonathan (eds.) (1999) Global transformations: politics, economics and culture. London: Polity Press.

Hemer, Oscar \& Tufte, Thomas (eds.)(2005) Media \& glocal change: rethinking communication for development. Buenos Aires: Consejo Latinoamericano de Ciencias Sociales (CLACSO) ; Göteborg: Nordicom.

Hemer, Oscar (2008) "Memories of a Modernity-to-be: some reflections on South Africa's unresolved dilemma", in Lindbladh, Johanna (ed.) The poetics of memory in post-totalitarian narration. Lund: Center for European Studies, Lund university.

Hemer, Oscar (2011) Writing Transition : Fiction and Truth in South Africa and Argentina. Diss. Oslo: Department of Social Anthropology, University of Oslo

Høg Hansen, Anders (2006) "Mapping space, conflict and identity". Glocal Times, issue 6.

Høg Hansen, Anders (2008) "Memorial and memory politics in Hamburg and Haifa", in Terho, Henri (ed.) Power and Culture: New Perspectives on Spatiality in European History. cliohres.net, 6th Framework Programme. 
Navarro, Dora (2009) "Transforming public space: a local radio's work in a poor urban community" in Development in Practice, Volume 19, Numbers 4-5, June 2009.

Navarro, Dora (2011) "Transformando el espacio público. El trabajo de una radio local religiosa en una comunidad urbana marginal", in Peruzzo, Cecilia M. Krohling, Thomas Tufte and Jair Vega Casanova (eds). 2011. Trazos de una otra Comunicación en América Latina: practicas comunitárias, teorías y demandas sociales. ALAIC y Ediciones Uninorte, Barranquilla, Colombia .

Nederveen Pieterse, Jan (2008) "Globalization the next round: Sociological perspectives". Futures, vol. 40, issue 8 .

Martin-Barbero (1993) Communication, Culture and Hegemony. From the Media to Mediation. London: Sage.

Richey, Lisa Ann \& Ponte, Stefano (2011) Brand aid: shopping well to save the world. Minneapolis: University of Minnesota Press.

Robertson, Roland (1992) Globalization: social theory and global culture. London: Sage.

Tawil-Souri, Helga (in progress) Digital Occupation: Infrastructures as Borders in Palestine/Israel

Tufte, Thomas (2006) Your future gets stuck! Challenges for HIV/AIDS communication. Media Development. London: WACC.

Tufte, Thomas \& Mefalopulos, Paolo (2009) Participatory Communication. World Bank.

Tufte, Thomas \& Enghel, Florencia (eds.)(2009) Youth engaging with the world: media, communication and social change. Göteborg: International Clearinghouse on Children, Youth and Media, Nordicom, University of Gothenburg

Tufte, Thomas (2011) "Mediapolis, human (in)security and citizenship communication and glocal development challenges in the digital era", in Christensen, Miyase, Jansson, André \& Christensen, Christian (red.) (2011). Online territories: globalization, mediated practice, and social space. New York: Peter Lang, pp. 113-131

Tufte, Thomas (In Press) Communication and Public Health in a Glocalized Context: Achievements and Challenges. In: Obregon, Rafael \& Waisbord, Silvio (eds.) Handbook on Global Health Communication. London: Blackwell-Wiley.

Wildermuth, Norbert (2010a) "Empowerment: the real challenge of digital inclusion”, in Drotner, Kirsten \& Schrøder, Kim Christian (red.) (2010). Digital content creation: perceptions, practices, \& perspectives. New York: Peter Lang.

Wildermuth, Norbert (2010b) "Media events and gendered identities in South Asia: Miss World going 'Deshi”", in Couldry, Hepp \& Krotz 2010. 